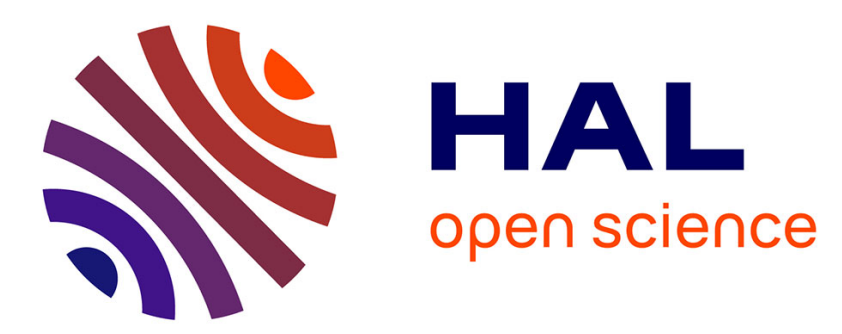

\title{
Morphological sorting of introduced freshwater fish species within and between donor realms \\ Guohuan Su, Sébastien Villéger, Sébastien Brosse
}

\section{To cite this version:}

Guohuan Su, Sébastien Villéger, Sébastien Brosse. Morphological sorting of introduced freshwater fish species within and between donor realms. Global Ecology and Biogeography, 2020, 29 (5), pp.803-813. 10.1111/geb.13054 . hal-03093245

\section{HAL Id: hal-03093245 \\ https://hal.science/hal-03093245}

Submitted on 3 Jan 2021

HAL is a multi-disciplinary open access archive for the deposit and dissemination of scientific research documents, whether they are published or not. The documents may come from teaching and research institutions in France or abroad, or from public or private research centers.
L'archive ouverte pluridisciplinaire HAL, est destinée au dépôt et à la diffusion de documents scientifiques de niveau recherche, publiés ou non, émanant des établissements d'enseignement et de recherche français ou étrangers, des laboratoires publics ou privés. 
Title: Morphological sorting of introduced freshwater fish species within and between donor realms

Running title: Global morphology of introduced fishes

$$
\text { Guohuan } \mathrm{Su}^{1 *} \text {, Sébastien Villéger }{ }^{2} \text {, Sébastien Brosse }{ }^{1}
$$

1 Laboratoire Evolution et Diversité Biologique (EDB), UMR5174, Université Toulouse 3 Paul Sabatier, CNRS, IRD, Toulouse, France

2 MARBEC, Univ Montpellier, CNRS, Ifremer, IRD, Montpellier, France

*Correspondence:

Guohuan Su, Laboratoire Evolution et Diversité Biologique, 118 Route de Narbonne, Toulouse 31062

CEDEX 9, France. Email: sugh39@163.com

\section{Acknowledgements}

SG has been funded by the China Scholarship Council. EDB laboratory was supported by 'Investissement d'Avenir' grants (CEBA, ANR-10-LABX-0025; TULIP, ANR-10-LABX-41). We are grateful to Aurèle Toussaint and Nicolas Charpin for help in data acquisition.

\section{Biosketch:}

Guohuan Su is a PhD student in the laboratory 'Evolution et Diversité Biologique' (University of Toulouse, France). He is interested in the macroecology and diversity of freshwater fish. $\mathrm{He}$ is currently investigating the morphological difference between non-native and native species in the freshwater fish fauna and the influence of global changes on global morphological and phylogenetic patterns.

Sébastien Villéger is a reasercher at the CNRS in Montpellier. He is interested in functional ecology of fishes and is particularly studying effect of global change on functional diversity of coastal fish assemblages.

Sébastien Brosse is a professor of Ecology in the University of Toulouse. He is interested in freshwater fish biodiversity patterns and processes across the globe, and on the influence of global changes on fish distribution at both macroecological and local scales. 


\begin{abstract}
Aim: To determine which morphological characteristics make a fish species a good candidate for introduction and establishment, we tested whether (1) introduced species differ in morphology from non-introduced species (species only existing in native areas and not introduced to new areas) in each donor assemblage (biogeographic realm fauna), (2) within the introduced species, the morphology of established species (self-sustaining introduced species) differs from that of the non-established species, (3) within the established species, those exported out of their native realm have more extreme morphological traits than those translocated within their native realm.
\end{abstract}

Major taxa studied: Freshwater fish.

Location: Global.

Time period: $1960 \mathrm{~s}-2010 \mathrm{~s}$

Methods: We used a global database of freshwater fishes from the six realms. Ten morphological traits were measured on 9,150 species. Principal component analysis was conducted to combine the ten traits into a multidimensional morphospace. We used PERMANOVA and PERMDISP2 to compare the distribution of species groups in the morphospace and Kolmogorov-Smirnov test to compare their distributions on PC axes.

Results: The morphology of introduced species differed from that of non-introduced species in all the six biogeographic realms. Among introduced species, established species had more extreme morphological traits than non-established species in most realms. Among established species, exported species had more extreme morphological traits than translocated species.

Main conclusions: Morphological differences between introduced and non-introduced species 
relies on an anthropogenic trait selection for fisheries and angling, leading to favor the introduction of predators, with large and laterally compressed bodies. Established species represent a small subset of introduced species morphologies, with species having more extreme morphological traits, probably making them more efficient on particular habitats than their nonestablished counterparts. This was particularly marked for fish morphologies adapted to lentic waters. Such a trend was triggered for exported species that have more extreme traits than translocated species.

\section{Keywords}

biogeographic realms, establishment, exported species, invasion steps, morphological traits, morphospace, rivers, translocated species. 


\section{Introduction}

Species invasion is one of the main drivers of the human-induced biodiversity crisis (Clavero \& García-Berthou, 2005; Leprieur, Beauchard, Blanchet, Oberdorff \& Brosse, 2008; Vitousek, D'antonio, Loope, Rejmanek \& Westbrooks, 1997). Biological invasions have altered patterns of biodiversity from local to continental scales and resulted in both ecological and economic impacts on entire ecosystems (Simberloff et al., 2013; Vitule, Freire \& Simberloff, 2009). Those detrimental impacts are at least in part due to the ecological differences between native species and introduced species that established in those recipient ecosystems. Introduced species establishing in new environments are most often larger than the species from the recipient faunas (Blackburn, Cassey \& Lockwood, 2009; Blanchet et al., 2010; Roy, Jablonski \& Valentine, 2002) and play distinct functions than those existing in recipient faunas (Marchetti, Moyle \& Levine, 2004; Toussaint et al., 2018). For instance, Olden, Poff and Bestgen (2006) showed that introduced fishes that established in the Colorado River (USA) occupy vacant niches and have distinct life-history strategies than the native species. Similarly, Blackburn et al. (2009) demonstrated that the establishment success of exotic birds increases with a particular combination of ecological traits.

Since human population and economic exchanges are identified as the key drivers of species introduction and establishment in new environments (Leprieur et al., 2008; Pyšek et al., 2010), the global population growth and accelerated economic development are predicted to increase the number of candidate species for introduction as well as their establishment success (Hulme, 2009; Seebens et al., 2017; Seebens et al., 2018). This is particularly true in freshwater ecosystems, which are among the most highly invaded ones (Moyle \& Marchetti, 2006), 
especially because several hundreds of fish species have been transported by humans outside their native range for the three last centuries (Leprieur et al., 2008; Toussaint et al., 2018).

Fish morphology was suggested to be related to the biological invasions in both marine and freshwater ecosystems (Azzurro et al., 2014; Blanchet et al., 2010; Ribeiro, Elvira, CollaresPereira \& Moyle, 2008). Up to now, it has been reported that established freshwater fish species (i.e. introduced species that successfully established in the new habitat) morphologically and functionally differ from the recipient fauna (e.g. Blanchet et al., 2010; Marchetti et al., 2004; Olden et al., 2006; Toussaint et al., 2018). Established species tend to be larger, with deeper bodies, and to have more piscivorous or detritivorous diets (Cucherousset, Blanchet \& Olden, 2012; Toussaint et al., 2018). However, functional diversity of fishes markedly varies between the six biogeographic realms, namely the Afrotropical, Australian, Neotropical, Nearctic, Oriental and Palearctic realms (Su, Villéger \& Brosse, 2019; Toussaint, Charpin, Brosse \& Villéger, 2016). Therefore, towards a better understanding of the causes and consequences of the invasion process of the world rivers, it is important to disentangle the relative importance of the natural functional differences between donor zones, the human preference for some functional characteristics and the capacity of each introduced species to establish (or not) in a new environment.

Tackling this challenge requires sequentially consider the introduction and establishment steps of the species invasion process, as proposed by Blackburn et al. (2011) and Lockwood, Hoopes and Marchetti (2013), within each realm. We therefore distinguished between nonintroduced species, which only exist in native areas and have never been introduced to new areas, and introduced species, which have at least once been introduced into areas (here river 
basins) where they did not historically occur (Figure 1a). We here tested the hypothesis that within each realm, humans select particular morphologies for the species to be introduced (Figure 1b). Once introduced, a species can establish or not in its new environment (Figure 1a). The success of establishment is largely influenced by the match between physical (climate, habitat) and biologic (competitors, predators and preys) environment and the capacities of the introduced species (Lockwood et al., 2013). A morphological difference between established and non-established species (Figure 1c) would therefore indicate trait-based filtering affecting the establishment success of introduced species (Moyle \& Marchetti, 2006). Moreover, translocated fishes that were introduced to nearby areas from their native range (i.e. within same realm) are more prone to adapt to local abiotic condition and biotic interactions than species exported to other realms, potentially facing markedly different conditions in those distant areas (Ribeiro et al., 2008). Thus, if physical and biological characteristics of the recipient environment differ between realms, we predict that functional characteristics of the exported species will differ from those of the translocated species, exported species being therefore more morphologically extreme than translocated species (Figure 1d). We applied this framework to the world freshwater fish faunas, considering more than 14,000 species from the 6 biogeographic realms.

\section{Materials and methods}

Fish occurrence was compiled from (Tedesco et al., 2017) which gathers the occurrence of 14,953 species (more than $90 \%$ of the freshwater fish species) in 3,119 drainage basins, covering more than $80 \%$ of the earth surface. Each occurrence is paired with a status, either 
native or non-native established if the species was not historically present in the drainage river basin. As more than $98 \%$ of the species historically belong to a single realm (Tedesco et al., 2017), we used this data to determine for each realm the list of native species that have been introduced and then established within their native realm (translocated species) or in at least another realm (exported species).

Distinguishing between introduced and non-introduced species cannot be done easily because there is no global database or realm scale record of introductions attempts (only successful introductions, i.e. established species, are recorded). Nevertheless, the introductions of vertebrates were mainly via intentional pathways to achieve various human purposes, including farming, ornament and gaming (Saul et al., 2017). This also holds for fishes and many studies have reported that freshwater fish introductions are driven by human interest (e.g. aquaculture, pest control, game fishing). Most freshwater fish species introductions are therefore intentional or at least human assisted (e.g. Gozlan, Britton, Cowx \& Copp, 2010; Leprieur et al., 2008; Marchetti et al., 2004; Padilla \& Williams, 2004). We thus collected the list of species of interest to humans from FishBase (Froese \& Pauly, 2018) and Blanchet et al. (2010), and these species were considered as those having higher chances to have been introduced in at least one river outside their native range (hereafter called introduced species). Within those introduced species, we then distinguished between non-established and established species using non-native occurrences from Tedesco et al. (2017). Since established species account for self-sustaining populations, populations of non-native species artificially maintained by constant release [e.g. rainbow trout (Oncorhynchus mykiss) in many European 
river basins, Stanković, Crivelli \& Snoj, 2015] were not considered as established (Tedesco et al., 2017).

Among the 14,953 species present in the occurrence database, 9,150 species were morphologically described using pictures and drawings from textbooks and scientific websites (Su et al., 2019). More precisely, morphology was assessed using ten traits describing the size and shape of body parts involved in food acquisition and locomotion (Toussaint et al., 2016; Villéger, Brosse, Mouchet, Mouillot \& Vanni, 2017). The ten traits were selected to be complementary, and they were indeed not markedly correlated to each other (Spearman test, rho $<0.45$ for all the 45 trait comparisons). More precisely, the fish size was described using the maximum body length (Max. Body Length) taken from FishBase (Froese \& Pauly, 2018). Those maximum body lengths were carefully reviewed, and irrelevant measures have been corrected according to appropriate literature. In addition to size, 11 morphological measures were assessed on side view pictures (Figure S1a) collected during an extensive literature review including our own field data and scientific literature sources made of peer-reviewed articles, books, and scientific websites. We collected at least one picture (photograph or scientific drawing) per species. Only good quality pictures and scientific side view drawings of entire adult animals, with confirmed species identification were kept. For species with marked sexual dimorphism, we considered male morphology, as female pictures are scarce for most species (especially for Perciformes and Cyprinodontiformes). Intraspecific morphological traits variability was not considered in this study as it hardly affects functional diversity at the large spatial resolution considered (Toussaint et al., 2018). The nine unitless traits describing the morphology of the fish head (including mouth and eye), body, pectoral and caudal fins (Figure 
$\mathrm{S} 1 \mathrm{~b})$ were computed as ratios between 11 morphological measures done using Image J software (http://rsb.info.nih.gov/ij/index.html). The 10 morphological traits ( 9 unitless ratios and body size) selected are commonly used in assessment of fish functional diversity (e.g. Bellwood, Goatley, Brandl \& Bellwood, 2014; Su et al., 2019; Toussaint et al., 2016; Villéger, Miranda, Hernandez \& Mouillot, 2010) and are linked to the feeding and locomotion functions of fish that themselves determine their contribution to key ecosystem processes such as controlling food webs and nutrient cycles (Villéger et al., 2017) (Figure S1b). Complementary functional traits, such as gut length, oral gape area and shape, were not included because they are currently only available for a few species. Some species have unusual morphologies (species without tails, flatfishes) that prevent from measuring some morphological traits. We thus applied conventions as mentioned in Su et al. (2019); Toussaint et al. (2016); Villéger et al. (2010) for these few exceptions.

Statistical analyses: Due to the lesion of body parts or the quality of fish pictures, some traits have not been measured for some species. Overall, $17.3 \%$ of the values were missing in the raw morphological traits dataset (from $6.8 \%$ for maximum body length to $24.5 \%$ for relative maxillary length). These missing values (NA) were replaced by estimates provided by a random forest algorithm called 'missForest' (Penone et al., 2014; Stekhoven \& Bühlmann, 2012). This method uses a random forest trained on the observed values of a data matrix to predict the missing values and automatically calibrates the filling values by a set of iterations (Stekhoven \& Bühlmann, 2012). It can be used to impute continuous and/or categorical data and is not biased by complex interactions and non-linear relations (Stekhoven \& Bühlmann, 2012). The efficiency of the Random Forest model used to fill missing values was tested on a set of 1,000 
species with complete values for all the ten traits. We randomly set $20 \%$ of the values for the 1,000 species as NA, and then used the 'missForest' to fill the NA with simulated values. We then compared the simulated values to the actual values. This procedure was repeated 999 times. Spearman's rho between actual and simulated data was used to measure the efficiency of the procedure. Spearman's rho varied from 0.89 to 0.96 , testifying for the efficiency of the method. As a comparison, we also tried to fill the NA by the average value of the trait for related species (genera). In this case, the Spearman's rho varies from 0.83 to 0.91 , which means that the 'missForest' procedure outperforms the classical imputation method consisting to fill the gaps using the average trait value of related species.

We then computed a principal component analysis (PCA) using values of the ten morphological traits for all the species (Maire, Grenouillet, Brosse \& Villéger, 2015). We assessed the robustness of our findings given traits accounted for, using a sensitivity procedure. We tested the effect of trait identity on the distance between species (i.e. Euclidean distance in the 5D space) by rerunning PCA based on all combinations of nine morphological traits out of ten. The distance between species was hardly affected by morphological traits accounted for (Mantel tests, $\mathrm{r}>0.900, P<0.001)$.

PERMANOVA and PERMDISP2 tests were conducted to compare the average and variance distributions of non-introduced, introduced, non-established, established, translocated and exported species in the morphological space in each realm and in the world. We then illustrated the distributions of these groups on the first five PC axes using transformed raincloud plots (Allen, Poggiali, Whitaker, Marshall \& Kievit, 2018), and compared distributions between groups using Kolmogorov-Smirnov tests (hereafter K-S tests). 
All statistical analyses were performed with R software version 3.3 (R Core Team, 2018). We used 'missForest' from 'missForest' R package (Stekhoven \& Bühlmann, 2012) to fill the missing trait values, 'adonis' and 'betadisper' functions from 'vegan' R package (Oksanen et al., 2010) to conduct the PERMANOVA and PERMDISP2 tests (Euclidean distance, permutations $=9,999$ ), and 'ks.test' function from 'stats' R package (R Core Team, 2018) to conduct the K-S tests.

\section{Results}

Among the 9,150 studied species, 2,690 species have been introduced while only 418 species (including 311 translocated species and 107 exported species) successfully established in the recipient assemblages. The remaining 2,272 introduced species failed to establish. Most of the non-established species originate from Afrotropical (877), Neotropical (651) and Oriental (475) realms. In contrast, most of the established species (translocated and exported species) originate from the Nearctic and Palearctic realms (129 and 105 translocated species in Nearctic and Palearctic realms, respectively, 34 and 39 exported species in Nearctic and Palearctic realms, respectively). The Australian realm hosts the least translocated species (18) and exported species (1) (Table S1). Exported species from the Australian realm were therefore not considered in the K-S test.

The first five PC axes explained $78.6 \%$ of the total variance among the world fish morphology (Figure S2). No axis was driven by a single trait and all traits contributed to the position of species in the functional space (Figure S2). PC1 axis shows a strong contribution of fish mouth size and position and therefore codes for trophic level, with higher trophic levels 
(predators) having positive values on this axis. PC2 axis shows a strong contribution of fish eye vertical position and body lateral shape and therefore codes for fish position in the water column, with benthic species having positive values on this axis. PC3 axis shows a strong contribution of body elongation and fin size. It therefore codes for habitat type and locomotion, with higher dispersal ability in slow-flowing habitats having positive values on this axis. PC4 is also strongly influenced by body elongation but also by fish body size, with large and laterally flattened fish represented by positive values. PC5 axis shows a strong contribution of caudal peduncle throttling and therefore code for locomotion, fish with higher dispersal ability having positive values on this axis (Figure S2). Overall, PC1, 2 and 4 accounted for both nutrition and locomotion, whereas PC3 and PC5 were mainly influenced by traits related to locomotion.

Introduced species occupied $58.22 \%$ of the global species pool in the $5 \mathrm{D}$ morphospace, which is higher than that of non-introduced species $(45.02 \%)$, although the number of introduced species is less than half of the non-introduced species. Intriguingly, within the introduced species, the morphospace occupied by non-established species $(56.58 \%)$ was almost the same than that of the introduced species, but the established species occupied only $7.15 \%$ of the global morphospace, which accounted for $1 / 8$ of the morphospace occupied by nonestablished species (Figure 2). A similar pattern was observed in all the six realms, in which the space occupied by introduced species was higher than the non-introduced species. This pattern was more pronounced in the two arctic realms. For instance, in the Nearctic realm, introduced species represent $40 \%$ of the species but more than $65 \%$ of the morphological space of the realm. The space occupied by non-established species varied from $38.56 \%$ to $44.18 \%$, whereas, the space occupied by established species varied from $0.22 \%$ to $5.08 \%$ (Figure 3 ). As subgroups of 
established species, translocated and exported species also occupied small portions of the morphospace filled by all the species from their respective realms (Figures 2 and 3 ).

At the world scale, groups of species had distinct distributions in the 5D morphospace (Figure 2), as testified by significant differences (PERMANOVA and PERMDISP2 tests) between all pairs of species groups, except for the translocated and exported species in the PERMDISP2 test (Table 1). At the realm scale, the non-introduced species were still significantly different from all the other groups belonging to the introduced species in all the six realms (Table 1). Examining those patterns for each axis confirmed this trend, to the exception of the Australian realm on PC1 and PC3, and of the Nearctic realm on PC5 (Figure S3).

Comparing the non-established and established species showed significant differences in the Afrotropical $(P=0.022)$, Neotropical $(P=0.038)$ and Oriental $(P=0.014)$ realms (PERMONOVA test, Table 1). Examining PC axes one-by-one showed that established species significantly differed from the non-established species on PC 3 and 4 in both the Afrotropical and Oriental realms. These two groups of species differed significantly on PC 2 and 4 in the Neotropical realm (Figure 4). Moreover, although not detected as significant difference by the PERMANOVA and PERMDISP2 tests, K-S tests detected significant differences between established and non-established species on PC 3, 4 and 5 in the Nearctic realm (Figure 4). In all the realms where the established species differed significantly from the non-established ones, the established species had higher PC4 values than the non-established species indicating larger and less elongated bodies (Figure 4). The established species showed the largest differences in values from the non-introduced species in all the significant 
comparisons, to the exception of Neotropical species on PC 2 (Figure 4).

Although an overall examination of translocated versus exported species revealed a significant difference only in the Nearctic realm (PERMANOVA and PERMDISP2 tests, Table 1), a more precise axis-by-axis examination reveals significant morphological differences on at least one out of the five PC axes in the five considered realms (the Australian realm was not considered as it has a single exported species). Generally, 9 out of the 25 comparisons between exported and translocated species in the 5 realms differed significantly. In Afrotropical and Nearctic realms, exported species were significantly different from the translocated species on PC 3, 4 and 5. They differed on PC3 in Neotropical realm, on PC1 in Oriental realm and on PC4 in Palearctic realm, respectively (Figure 5). In all the realms where the exported species differed significantly from the translocated ones, the exported species had larger and less elongated bodies (PC4) and higher caudal peduncle throttling values (PC5) than the translocated species (Figure 5). The exported species showed the largest difference in values from the nonintroduced species in all the significant comparisons (Figure 5).

\section{Discussion}

Across the globe, less than $20 \%$ of the known freshwater fish fauna has been used for various human purposes including fisheries, aquaculture, angling, and ornament (Froese \& Pauly, 2018). Assuming that these species of interest for humans have at least once been introduced in a river basin where they do not naturally occur appears realistic for two main reasons. First, $71.5 \%$ of the established species listed by Tedesco et al. (2017) belong to this category; and second, current records of introduction attempts, although regional and/or incomplete, report that 
introduced species are those having an interest for humans (Lintermans, 2004; Welcomme, 1988). The species of interest for humans, here considered as introduced species have particular morphological traits distinguishing them from the non-introduced species. Moreover, the morphological space occupied by these species is greater than that of the non-introduced species, although representing less than one-third of the non-introduced species (2272 vs 6460 species). Humans have therefore selected fish species with various morphological characteristics, despite a high functional redundancy of native species (Su et al., 2019). Such extended morphological selection of introduced species is consistent in all the six realms, and reflects distinct introduction purposes. The selection of large-bodied predators is associated with angling purposes, whereas laterally flattened species account for species inhabiting slow-flowing habitats that are often tolerant toward water quality and oxygen content and therefore easy to rear in aquaculture ponds (Blake, 1983; Haas, Blum \& Heins, 2010). In contrast, the selection of extreme morphologies can be afforded to ornamental trade (Howeth et al., 2016; Moyle \& Marchetti, 2006). Contrary to introduced species, established species occupy a reduced volume of the world morphospace (less than $8 \%$ ), indicating that the species that established at least in one river basin where they do not historically occur have homogeneous and similar morphologies. Established species consistently have larger and more laterally compressed bodies than the non-established species in the six realms. This pattern reflects a marked environmental filtering effect at the establishment stage, that reinforce the introduction trend toward species with larger body sizes and more lateral compressed bodies. Fishes with laterally compressed bodies have high maneuverability and perform sustained swimming more efficiently in slow-flowing habitats (Blake, 1983; Haas, Blum \& Heins, 2010). Thus, the global 
rise of river fragmentation and dams construction, which are known to facilitate the establishment of introduced species (Havel, Lee \& Vander Zanden, 2005; Johnson, Olden \& Vander Zanden, 2008) throughout the world (Anderson et al., 2018; Winemiller et al., 2016; Zarfl, Lumsdon, Berlekamp, Tydecks \& Tockner, 2015) can partly illustrate the pattern of morphological trait distributions of the established species. In addition, it should be noticed that established species from industrialized realms (Palearctic and Nearctic) have more diverse morphologies than those from the other realms (14 to $16 \%$ of the realm morphological space for Palearctic and Nearctic realms vs less than 3\% for the four other realms). This could be afforded to a higher number of introduction events per species (i.e. propagule pressure), that are known to notably increase establishment probability (Lockwood, Cassey \& Blackburn, 2005). Among established species, the morphological difference between the translocated and the exported species was due to both differences in the species selected by humans to be introduced, and to different strengths of environmental filters, favoring the establishment of the most extreme morphologies in exported species. Indeed, most of the exported freshwater fish species result from the establishment of species intentionally introduced in one or several realms where the species do not naturally occur, whereas translocated species result from the establishment of species introduced intentionally or not. Hence, within a realm, short distance transport to nearby basins is easy and largely used by anglers to illegally spread some species of interest, but also to spread other accompanying species, such as baits. For instance, the introduction and spread of wels catfish (Silurus glanis) from eastern to western European rivers have largely been assisted by anglers (Cucherousset et al., 2018). Such short distance transport has also been recorded in the Neotropics for a series of harvested species including Siluriforms 
(Pseudoplatystoma sp.), Characiforms (Curimata sp.) or Osteoglossiforms (Arapaima gigas)

(Bezerra et al., 2019; Vitule et al., 2019). In contrast, exportations are more difficult, as they need to maintain fish alive across long distances, and therefore a careful selection of the species to be introduced, often for commercial reasons. This discrepancy between translocation and exportation processes explains the morphological difference between the translocated and exported species, the latter being the largest and the most laterally flattened species, traits often researched for aquaculture species. Interestingly, this trend was true for Palearctic, Nearctic and Afrotropical species, but not for Neotropical fishes, probably because Neotropical fish account for most of the ornamental fish species, some establishing as exported species. It is, for instance, the case for the guppy, Poecilia reticulata, which originates from the Neotropical realm, but established in all realms following its introduction as an ornamental fish (Deacon, Ramnarine \& Magurran, 2011). Those ornamental fish have various morphologies, but are often small sized, counterbalancing therefore the trend toward the large body sized exported fishes found in the other realms. The distinct pattern between exported and translocated species observed across realms testifies for distinct human selection modes of exported and translocated species, but can also reflect distinct establishment processes between the realms, paralleling the results of Blanchet et al. (2010) demonstrating discrepancies in establishment determinants between realms. Indeed, within a realm, a translocated species will encounter similar environments to its native range and will share its new habitat with species shaped by the same regional evolutionary constraints (Colautti, Eckert \& Barrett, 2010). In contrast, an exported species has to face with a fauna that evolved under a distinct regional history (Nekola \& White, 1999). 
To conclude, fish morphological traits are closely related to the introduction and establishment stages of the invasive process. Human selection affects the introductions stage, and select a subset of the realm fish morphology reflecting a preference towards large pelagic predators with high dispersal ability. However, environmental filtering profoundly reshapes the morphology of established species. The $c a .400$ introduced species that established (out of $c a$. 2700 introduced species) are the most laterally flattened, and inhabit slow-flowing habitats (e.g. lakes, reservoirs), therefore reinforcing that morphological selection achieved by humans at the introduction stage. Nevertheless, the recent development of ornamental fish trade associated with the global rise of leisure activities might lead to a considerable change of human interest for particular morphological traits. Those traits will be markedly different from the traits of interest for aquaculture or angling species. That will probably lead, as initiated in the Neotropics, to the introduction of an extended range of morphologies, and will increase the pool of introduced species in the future. In the same way, the economic development of tropical countries (e.g. China in Oriental realm and Brazil in Neotropical realm) makes them providers of new non-native species through local aquaculture, aquarium and angling development (Vitule et al., 2009; Vitule, Skóra \& Abilhoa, 2012; Vitule et al., 2019). This trend might thus increase in the near future the diversity of established species in the tropical realms. Among those new pools of introduced species, some might establish in the recipient environments and cause profound functional changes to the recipient communities. Given that once established, eradicating an introduced species is often impossible, we call for a particular caution against non-native species introductions (Vitule et al., 2009). 


\section{Data accessibility}

Fish occurrence data can be freely retrieved at https://doi.org/10.6084/m9.figshare.c.3739145 and metadata are available in Tedesco et al. (2017). Fishes maximum body lengths were downloaded from FishBase (http://www.fishbase.org). Information about the 9,150 species with combined trait values (PC1-PC5) used in this study are available in Su et al. (2019). 


\section{References}

Allen, M., Poggiali, D., Whitaker, K., Marshall, T.R. \& Kievit, R. (2018) Raincloud plots: a multi-platform tool for robust data visualization. PeerJ Preprints, 6, e27137v1.

Anderson, E.P., Jenkins, C.N., Heilpern, S., Maldonado-Ocampo, J.A., Carvajal-Vallejos, F.M., Encalada, A.C., Rivadeneira, J.F., Hidalgo, M., Cañas, C.M., Ortega, H., Salcedo, N. Maldonado, M. \& Tedesco, P.A. (2018) Fragmentation of Andes-to-Amazon connectivity by hydropower dams. Science advances, 4, eaao1642.

Azzurro, E., Tuset, V.M., Lombarte, A., Maynou, F., Simberloff, D., Rodríguez-Pérez, A. \& Sol é, R.V. (2014) External morphology explains the success of biological invasions. Ecology letters, 17, 1455-1463.

Bellwood, D., Goatley, C., Brandl, S. \& Bellwood, O. (2014) Fifty million years of herbivory on coral reefs: fossils, fish and functional innovations. Proceedings of the Royal Society B: Biological Sciences, 281, 20133046.

Bezerra, L.A.V., Freitas, M.O., Daga, V.S., Occhi, T.V.T., Faria, L., Costa, A.P.L., Padial, A.A., Prodocimo, V. \& Vitule, J.R.S. (2019) A network meta-analysis of threats to South American fish biodiversity. Fish and Fisheries, 20, 620-639.

Blackburn, T.M., Cassey, P. \& Lockwood, J.L. (2009) The role of species traits in the establishment success of exotic birds. Global Change Biology, 15, 2852-2860.

Blackburn, T.M., Pyšek, P., Bacher, S., Carlton, J.T., Duncan, R.P., Jarošík, V., Wilson, J.R. \& Richardson, D.M. (2011) A proposed unified framework for biological invasions. Trends in ecology \& evolution, 26, 333-339.

Blake, R.W. (1983) Fish locomotion. Cambridge University Press, Cambridge, UK.

Blanchet, S., Grenouillet, G., Beauchard, O., Tedesco, P.A., Leprieur, F., Dürr, H.H., Busson, F., Oberdorff, T. \& Brosse, S. (2010) Non-native species disrupt the worldwide patterns of freshwater fish body size: implications for Bergmann's rule. Ecology Letters, 13, 421 431.

Clavero, M. \& García-Berthou, E. (2005) Invasive species are a leading cause of animal extinctions. Trends in ecology \& evolution, 20, 110. 
Colautti, R.I., Eckert, C.G. \& Barrett, S.C. (2010) Evolutionary constraints on adaptive evolution during range expansion in an invasive plant. Proceedings of the Royal Society B: Biological Sciences, 277, 1799-1806.

Cucherousset, J., Blanchet, S. \& Olden, J.D. (2012) Non-native species promote trophic dispersion of food webs. Frontiers in Ecology and the Environment, 10, 406-408.

Cucherousset, J., Horky, P., Slavík, O., Ovidio, M., Arlinghaus, R., Boulêtreau, S., Britton, R., García-Berthou, E. \& Santoul, F. (2018) Ecology, behaviour and management of the European catfish. Reviews in Fish Biology and Fisheries, 28, 177-190.

Deacon, A.E., Ramnarine, I.W. \& Magurran, A.E. (2011) How reproductive ecology contributes to the spread of a globally invasive fish. PLoS One, 6, e24416.

Froese, R. \& Pauly, D. (2018) Fishbase. In. World Wide Web electronic publication

Gozlan, R.E., Britton, J., Cowx, I. \& Copp, G. (2010) Current knowledge on non-native freshwater fish introductions. Journal of fish biology, 76, 751-786.

Haas, T.C., Blum, M.J. \& Heins, D.C. (2010) Morphological responses of a stream fish to water impoundment. Biology letters, 6, 803-806.

Havel, J.E., Lee, C.E. \& Vander Zanden, J.M. (2005) Do reservoirs facilitate invasions into landscapes? BioScience, 55, 518-525.

Howeth, J.G., Gantz, C.A., Angermeier, P.L., Frimpong, E.A., Hoff, M.H., Keller, R.P., Mandrak, N.E., Marchetti, M.P., Olden, J.D. \& Romagosa, C.M. (2016) Predicting invasiveness of species in trade: climate match, trophic guild and fecundity influence establishment and impact of non-native freshwater fishes. Diversity \& Distributions, 22, 148-160.

Hulme, P.E. (2009) Trade, transport and trouble: managing invasive species pathways in an era of globalization. Journal of applied ecology, 46, 10-18.

Johnson, P.T., Olden, J.D. \& Vander Zanden, M.J. (2008) Dam invaders: impoundments facilitate biological invasions into freshwaters. Frontiers in Ecology and the Environment, 6, 357-363.

Leprieur, F., Beauchard, O., Blanchet, S., Oberdorff, T. \& Brosse, S. (2008) Fish invasions in the world's river systems: when natural processes are blurred by human activities. Plos Biology, 6, e28. 
Lintermans, M. (2004) Human-assisted dispersal of alien freshwater fish in Australia. New Zealand Journal of Marine and Freshwater Research, 38, 481-501.

Lockwood, J.L., Cassey, P. \& Blackburn, T. (2005) The role of propagule pressure in explaining species invasions. Trends in ecology \& evolution, 20, 223-228.

Lockwood, J.L., Hoopes, M.F. \& Marchetti, M.P. (2013) Invasion ecology. John Wiley \& Sons. Maire, E., Grenouillet, G., Brosse, S. \& Villéger, S. (2015) How many dimensions are needed to accurately assess functional diversity? A pragmatic approach for assessing the quality of functional spaces. Global Ecology and Biogeography, 24, 728-740.

Marchetti, M.P., Moyle, P.B. \& Levine, R. (2004) Invasive species profiling? Exploring the characteristics of non-native fishes across invasion stages in California. Freshwater biology, 49, 646-661.

Moyle, P.B. \& Marchetti, M.P. (2006) Predicting invasion success: freshwater fishes in California as a model. Bioscience, 56, 515-524.

Nekola, J.C. \& White, P.S. (1999) The distance decay of similarity in biogeography and ecology. Journal of Biogeography, 26, 867-878.

Oksanen, J., Blanchet, F.G., Kindt, R., Legendre, P., O’hara, R., Simpson, G.L., Solymos, P., Stevens, M.H.H. \& Wagner, H. (2010) Vegan: community ecology package. R package

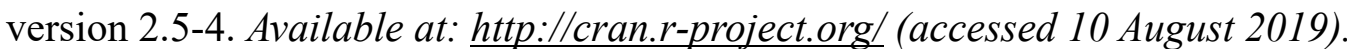

Olden, J.D., Poff, N.L. \& Bestgen, K.R. (2006) Life-history strategies predict fish invasions and extirpations in the Colorado River Basin. Ecological Monographs, 76, 25-40.

Padilla, D.K. \& Williams, S.L. (2004) Beyond ballast water: aquarium and ornamental trades as sources of invasive species in aquatic ecosystems. Frontiers in Ecology and the Environment, 2, 131-138.

Penone, C., Davidson, A.D., Shoemaker, K.T., Di Marco, M., Rondinini, C., Brooks, T.M., Young, B.E., Graham, C.H. \& Costa, G.C. (2014) Imputation of missing data in lifehistory trait datasets: which approach performs the best? Methods in Ecology and Evolution, 5, 961-970.

Pyšek, P., Jarošík, V., Hulme, P.E., Kühn, I., Wild, J., Arianoutsou, M., Bacher, S., Chiron, F., Didžiulis, V. \& Essl, F. (2010) Disentangling the role of environmental and human pressures on biological invasions across Europe. Proceedings of the National Academy 
of Sciences, 107, 12157-12162.

R Core Team (2018) R: A Language and Environment for Statistical Computing. Retrieved from https://www.r-project.org/

Ribeiro, F., Elvira, B., Collares-Pereira, M.J. \& Moyle, P.B. (2008) Life-history traits of nonnative fishes in Iberian watersheds across several invasion stages: a first approach. Biological Invasions, 10, 89-102.

Roy, K., Jablonski, D. \& Valentine, J.W. (2002) Body size and invasion success in marine bivalves. Ecology Letters, 5, 163-167.

Saul, W.C., Roy, H.E., Booy, O., Carnevali, L., Chen, H.J., Genovesi, P., Harrower, C.A., Hulme, P.E., Pagad, S. \& Pergl, J. (2017) Assessing patterns in introduction pathways of alien species by linking major invasion data bases. Journal of Applied Ecology, 54, 657-669.

Seebens, H., Blackburn, T.M., Dyer, E.E., Genovesi, P., Hulme, P.E., Jeschke, J.M., Pagad, S., Pyšek, P., Winter, M. \& Arianoutsou, M. (2017) No saturation in the accumulation of alien species worldwide. Nature communications, 8, 14435.

Seebens, H., Blackburn, T.M., Dyer, E.E., Genovesi, P., Hulme, P.E., Jeschke, J.M., Pagad, S., Pyšek, P., van Kleunen, M. \& Winter, M. (2018) Global rise in emerging alien species results from increased accessibility of new source pools. Proceedings of the National Academy of Sciences, 115, E2264-E2273.

Simberloff, D., Martin, J.-L., Genovesi, P., Maris, V., Wardle, D.A., Aronson, J., Courchamp, F., Galil, B., García-Berthou, E. \& Pascal, M. (2013) Impacts of biological invasions: what's what and the way forward. Trends in ecology \& evolution, 28, 58-66.

Stanković, D., Crivelli, A.J. \& Snoj, A. (2015) Rainbow trout in Europe: introduction, naturalization, and impacts. Reviews in Fisheries Science \& Aquaculture, 23, 39-71.

Stekhoven, D.J. \& Bühlmann, P. (2012) MissForest—non-parametric missing value imputation for mixed-type data. Bioinformatics, 28, 112-118.

Su, G., Villéger, S. \& Brosse, S. (2019) Morphological diversity of freshwater fishes differs between realms, but morphologically extreme species are widespread. Global Ecology and Biogeography, 28, 211-221.

Tedesco, P.A., Beauchard, O., Bigorne, R., Blanchet, S., Buisson, L., Conti, L., Cornu, J.-F., Dias, M.S., Grenouillet, G. \& Hugueny, B. (2017) A global database on freshwater fish 
species occurrence in drainage basins. Scientific Data, 4, 170141.

Toussaint, A., Charpin, N., Brosse, S. \& Villéger, S. (2016) Global functional diversity of freshwater fish is concentrated in the Neotropics while functional vulnerability is widespread. Scientific reports, 6, 22125.

Toussaint, A., Charpin, N., Beauchard, O., Grenouillet, G., Oberdorff, T., Tedesco, P.A., Brosse, S. \& Villéger, S. (2018) Non-native species led to marked shifts in functional diversity of the world freshwater fish faunas. Ecology letters, 21, 1649-1659.

Villéger, S., Miranda, J.R., Hernandez, D.F. \& Mouillot, D. (2010) Contrasting changes in taxonomic vs. functional diversity of tropical fish communities after habitat degradation. Ecological Applications, 20, 1512-1522.

Villéger, S., Brosse, S., Mouchet, M., Mouillot, D. \& Vanni, M.J. (2017) Functional ecology of fish: current approaches and future challenges. Aquatic Sciences, 79, 783-801.

Vitousek, P.M., D'antonio, C.M., Loope, L.L., Rejmanek, M. \& Westbrooks, R. (1997) Introduced species: a significant component of human-caused global change. New Zealand Journal of Ecology, 21, 1-16.

Vitule, J.R., Occhi, T.V., Kang, B., Matsuzaki, S.-I., Bezerra, L.A., Daga, V.S., Faria, L., Frehse, F.d.A., Walter, F. \& Padial, A.A. (2019) Intra-country introductions unraveling global hotspots of alien fish species. Biodiversity and Conservation, 28, 3037-3043.

Vitule, J.R.S., Freire, C.A. \& Simberloff, D. (2009) Introduction of non-native freshwater fish can certainly be bad. Fish \& Fisheries, 10, 98-108.

Vitule, J.R.S., Skóra, F. \& Abilhoa, V. (2012) Homogenization of freshwater fish faunas after the elimination of a natural barrier by a dam in Neotropics. Diversity and Distributions, 18, $111-120$.

Welcomme, R.L. (1988) International introductions of inland aquatic species. Food \& Agriculture Org.

Winemiller, K.O., McIntyre, P., Castello, L., Fluet-Chouinard, E., Giarrizzo, T., Nam, S., Baird, I., Darwall, W., Lujan, N. \& Harrison, I. (2016) Balancing hydropower and biodiversity in the Amazon, Congo, and Mekong. Science, 351, 128-129.

Zarfl, C., Lumsdon, A.E., Berlekamp, J., Tydecks, L. \& Tockner, K. (2015) A global boom in hydropower dam construction. Aquatic Sciences, 77, 161-170. 
1 Table 1 Differences in traits distributions (average and variance) between fish groups tested using PERMANOVA and PERMDISP2 ( $P$-values on

2 left and right sides of semi-column, respectively, $P$-values lower than 0.05 are bolded). Results are given for freshwater fish species from each

3 realm and for the world fish fauna. See text for explanations about fish groups.

\begin{tabular}{|c|c|c|c|c|c|c|c|}
\hline & Afrotropical & Australian & Nearctic & Neotropical & Oriental & Palearctic & World \\
\hline Non-introduced vs Introduced & $<0.001 ;<0.001$ & $<0.001 ;<0.001$ & $<0.001 ;<0.001$ & $<0.001 ;<0.001$ & $<0.001 ;<0.001$ & $<0.001 ;<0.001$ & $<0.001 ;<0.001$ \\
\hline Non-introduced vs Non-established & $<0.001 ;<0.001$ & $<0.001 ;<0.001$ & $<0.001 ;<0.001$ & $<0.001 ;<0.001$ & $<0.001 ;<0.001$ & $<0.001 ;<0.001$ & $<0.001 ;<0.001$ \\
\hline Non-introduced vs Established & $<0.001 ;<0.001$ & $<0.001 ;<0.001$ & $<0.001 ;<0.001$ & $<0.001 ;<0.001$ & $<0.001 ;<0.001$ & $<0.001 ;<0.001$ & $<0.001 ;<0.001$ \\
\hline Non-established vs Established & $\mathbf{0 . 0 2 2} ; 0.241$ & $0.724 ; 0.860$ & $0.915 ; 0.145$ & $\mathbf{0 . 0 3 8} ; 0.176$ & $\mathbf{0 . 0 1 4} ; 0.052$ & $0.189 ; 0.109$ & $<0.001 ;<0.001$ \\
\hline Non-introduced vs Translocated & $<0.001 ;<0.001$ & $0.004 ;<0.001$ & $<0.001 ;<0.001$ & $<0.001 ;<0.001$ & $<0.001 ;<0.001$ & $<0.001 ;<0.001$ & $<0.001 ;<0.001$ \\
\hline Non-introduced vs Exported & $<0.001 ; 0.014$ & $\mathbf{0 . 0 4 8} ; \mathrm{NA}$ & $<0.001 ;<0.001$ & $<0.001 ;<0.001$ & $<0.001 ; 0.002$ & $<0.001 ;<0.001$ & $<0.001 ;<0.001$ \\
\hline Translocated vs Exported & $0.651 ; 0.735$ & 0.108 ; NA & $<0.001 ;<0.001$ & $0.778 ; 0.403$ & $0.292 ; 0.179$ & $0.208 ; 0.884$ & $\mathbf{0 . 0 3 1} ; 0.334$ \\
\hline
\end{tabular}


8 Figure 1 Assessing the difference in morphological trait values between groups of freshwater

9 fish species. (a) Conceptual representation of non-introduced, non-established, established, translocated and exported species based on their distribution in a realm (realm A) and in the world (other realms). A non-introduced species has never been introduced in a river basin where it did not historically occur. An introduced species has been introduced to river basins where it did not historically occur. An introduced species becomes established if it creates a selfsustaining population where it has been introduced. Within the established species, a translocated species has established within its native realm in one or several river basins where it did not historically occur and an exported species has been introduced and established at least in one river basin from a biogeographic realm where the species did not historically occur. Three tests of difference in the distribution of trait values were successively conducted between: (b) the non-introduced and introduced species; (c) the non-introduced, non-established and established species; (d) the non-introduced, translocated and exported species.

21

a)
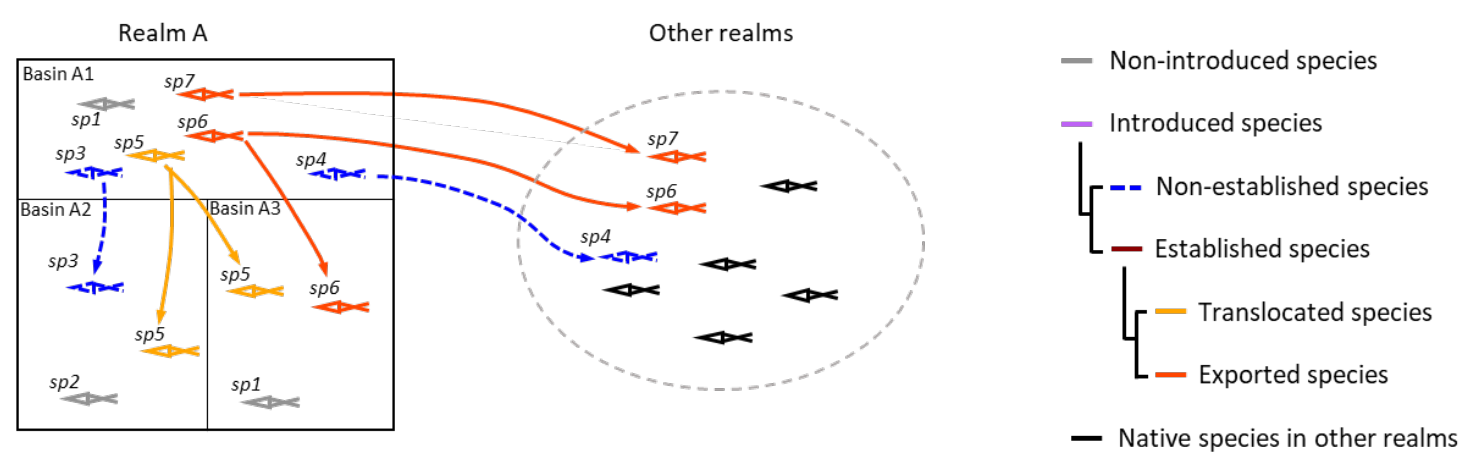

b)

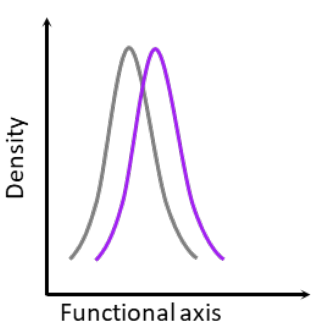

c)

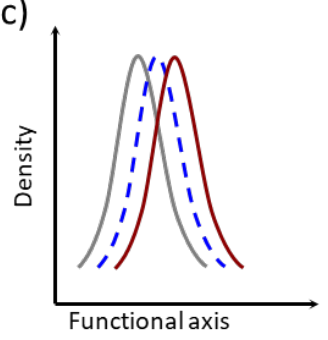

d)

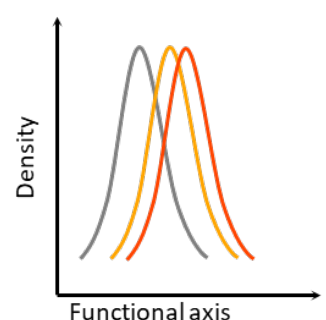

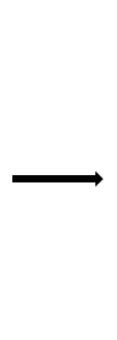


Figure 2 Distribution of the different groups of species in the five dimensional morphological space of the world fish fauna. Morphological traits with high relative contribution to a PC axis (>15\%) are shown (See supplementary Figure S1 for a complete view of the contribution of the 10 morphological traits to the $5 \mathrm{PC}$ axes). Purple to yellow shade indicates increasing species density. Values after the legends show the percentage of

5D morphospace volume occupied by each group in the global species pool.
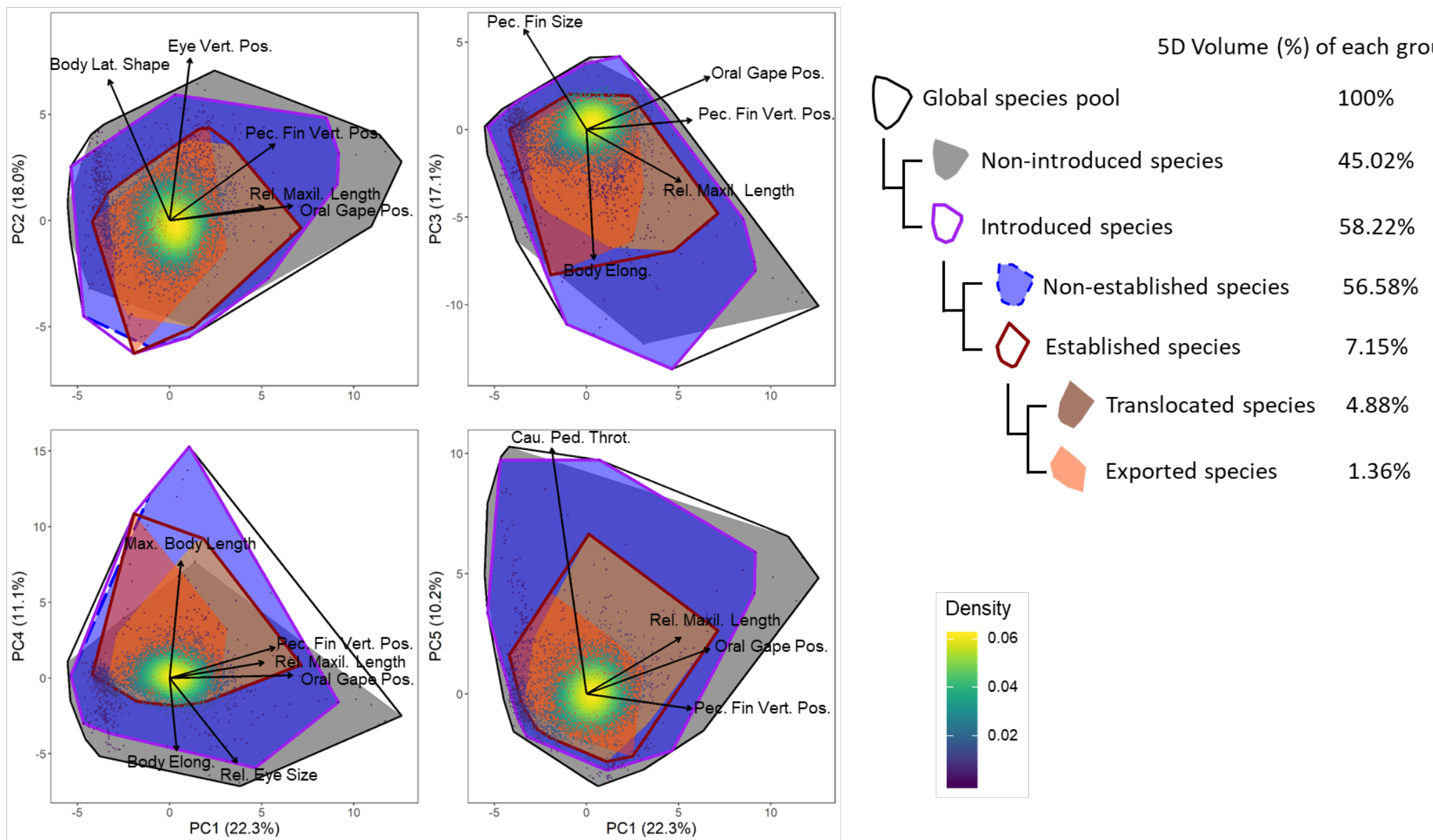
Figure 3 Distributions of the different groups of species in the five dimensional morphological space for each realm. Values in the table show the

percentage of 5D morphospace volume occupied by each group in the realm species pool.

$$
\text { Global species pool }
$$

5D Volume (\%) of each group Realm species pool Non-introduced species Introduced species

Non-established species Established species Translocated species

Exported species
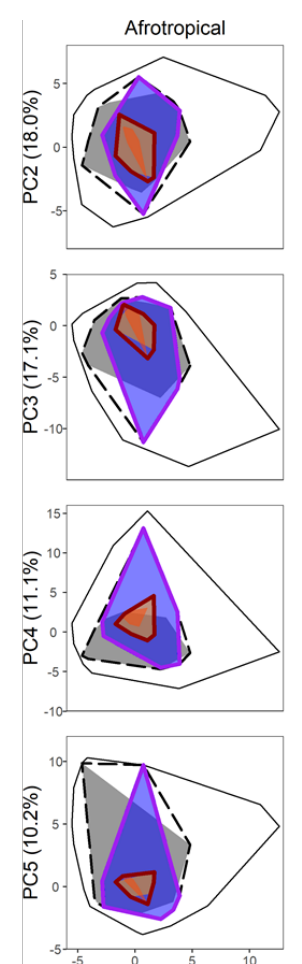

PC1 $(22.3 \%)^{10}$
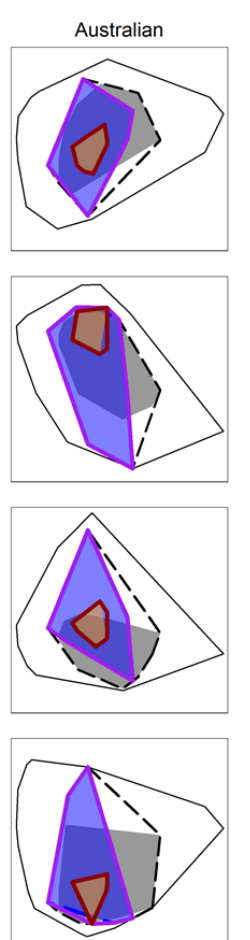
Afrotropical $100.00 \%$ $29.54 \%$ $39.60 \%$

$38.56 \%$

$0.25 \%$

$0.14 \%$

$<0.01 \%$
PC1 $(22.3 \%){ }^{i 0}$
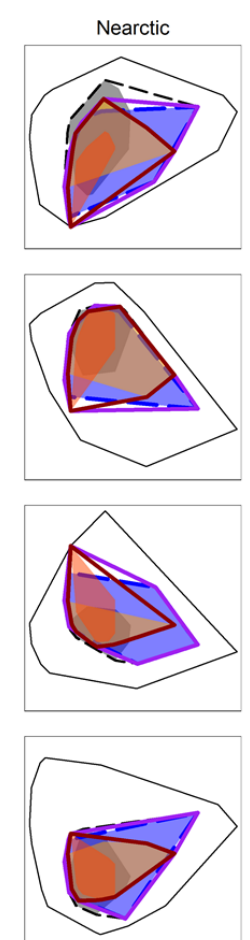

PC1 $(22.3 \%)^{i 0}$ Australian $100.00 \%$ $26.30 \%$ $40.50 \%$ $39.05 \%$

$0.22 \%$

$0.20 \%$

$0.00 \%$

Nearctic

$100.00 \%$

$14.48 \%$

$66.58 \%$

$40.45 \%$

$15.03 \%$

$8.09 \%$

$1.03 \%$
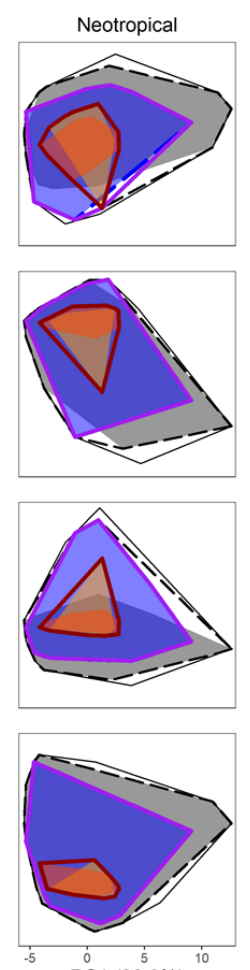

PC1 $(22.3 \%)^{10}$
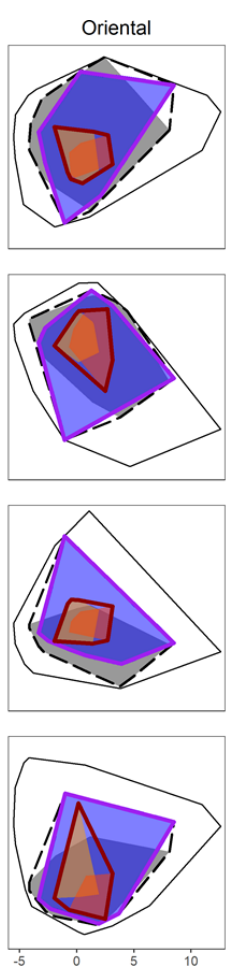

PC1 $\stackrel{i}{5}$ (22.3\%) Oriental

$100.00 \%$

$29.60 \%$

$46.34 \%$

$44.18 \%$

$2.04 \%$

$0.52 \%$

$0.24 \%$
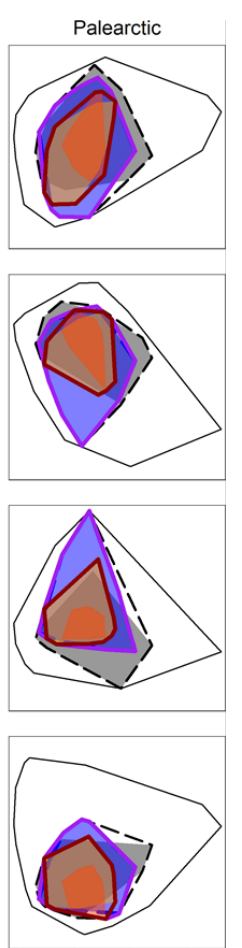

$\stackrel{0}{\operatorname{PC}}(22.3 \%)^{i 0}$ Palearctic

$100.00 \%$

$31.73 \%$

$48.73 \%$

$32.24 \%$

$14.33 \%$

$8.85 \%$

$1.56 \%$ 
Figure 4 Density distribution of species on the 5 PC axes for non-introduced, non-established and established species in each realm. Boxplots and results of K-S test between the non-established and established species are shown beside each plot item $\left(* * * P<0.001,{ }^{* *} P<0.01,{ }^{*} P<0.05\right)$.

33 (See the supplementary Table S2 for the complete K-S test between the three groups)

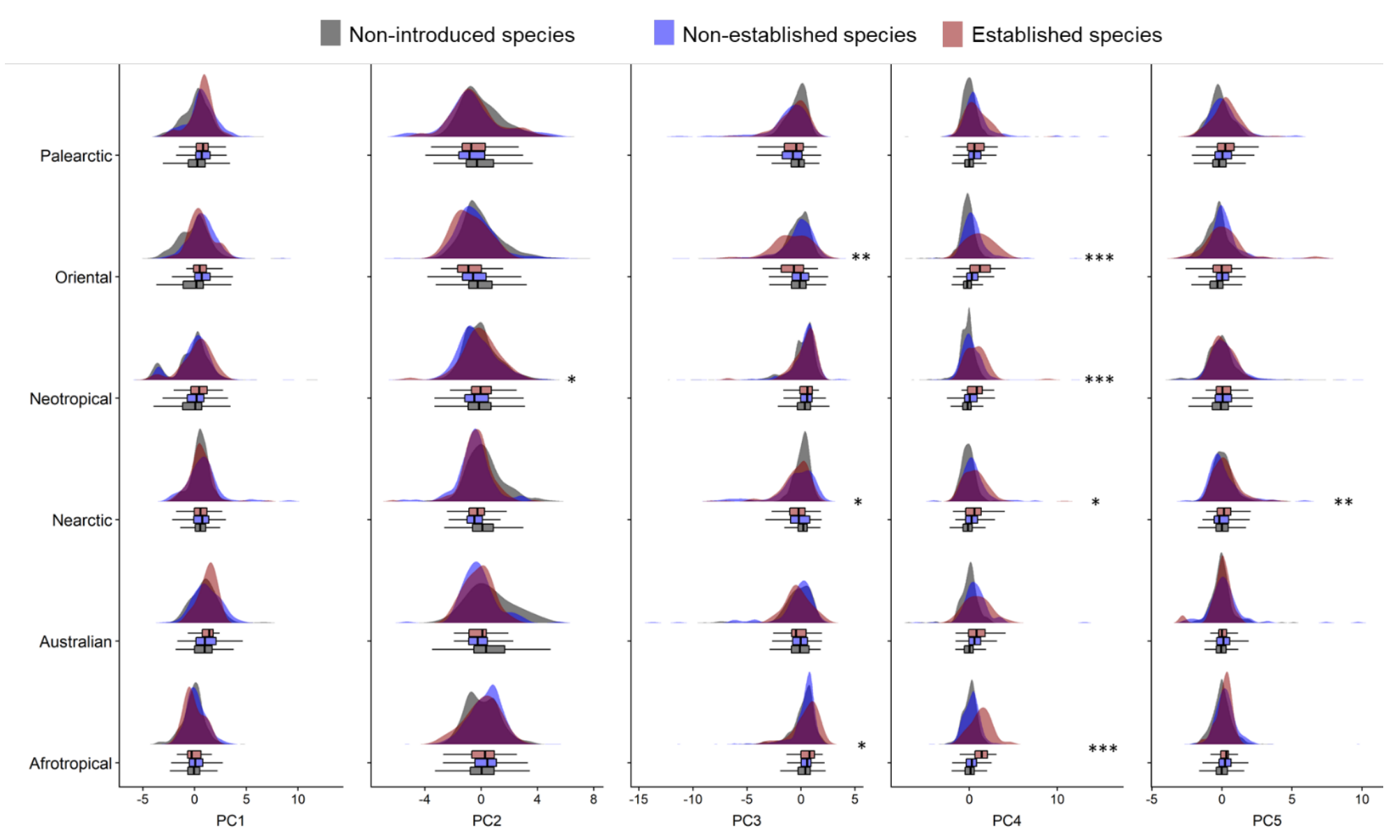


Figure 5 Density distribution of species on the 5 PC axes for non-introduced, translocated and exported species in each realm. Boxplots and results of K-S test between the translocated and exported species are shown beside each plot item (*** $P<0.001,{ }^{* *} P<0.01, * P<0.05$ ). (See the supplementary Table S2 for the complete K-S test between the three groups)

38

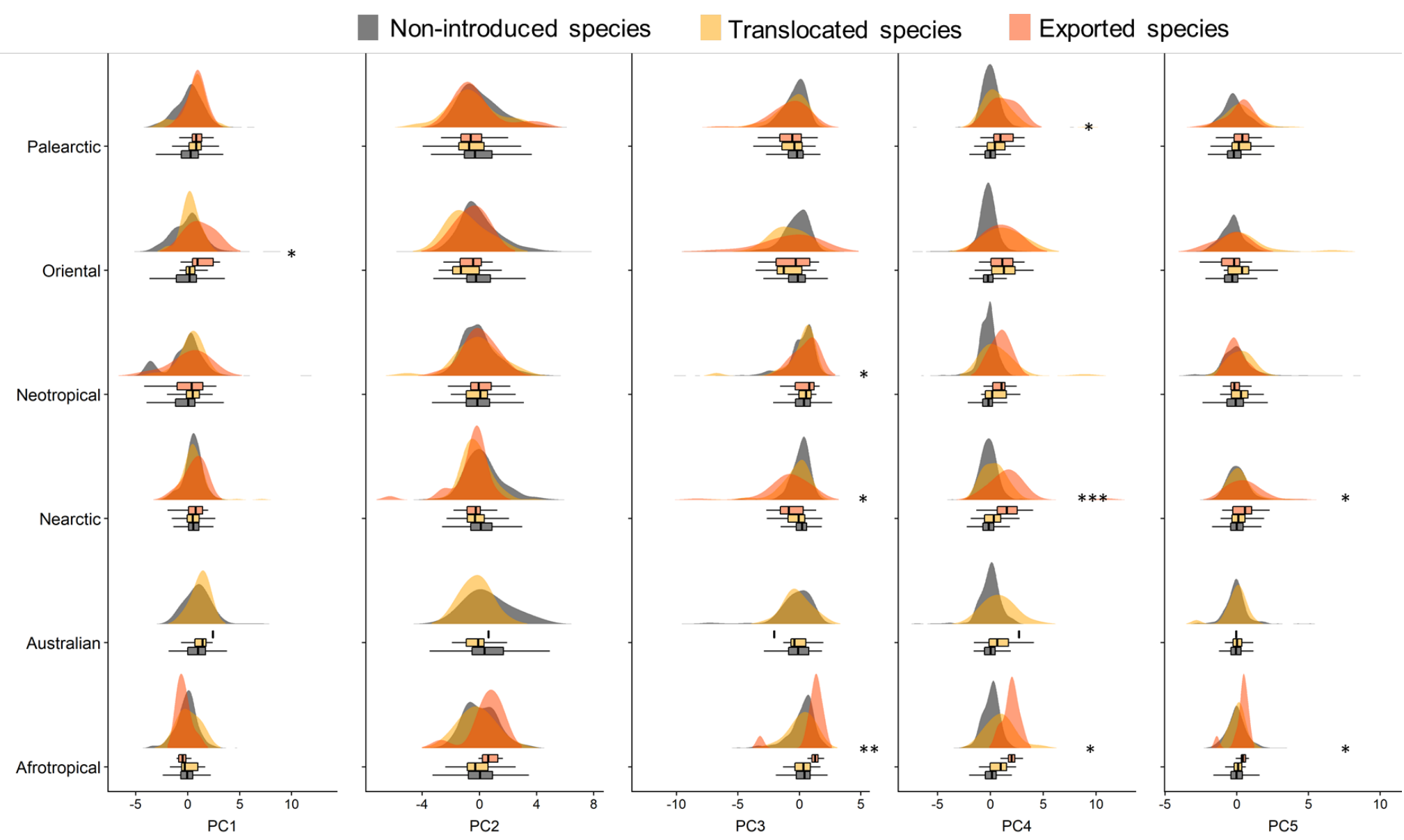

PC5 